\title{
A simple new technique for neo-umbilicoplasty ${ }^{\text {it }}$
}

\author{
M. Pfulg*, K. Van de Sijpe, Ph. Blondeel \\ Laclinic Montreux, Avenue de Collonge, 43, 1820 Montreux-Territet, Switzerland
}

Received 21 June 2004; accepted 11 January 2005

\author{
KEYWORDS \\ Umbilicus; \\ Neo-umbilicoplasty; \\ Umbilicoplasty; \\ Abdominoplasty
}

\begin{abstract}
Summary This article describes a new technique for reconstruction of the umbilicus. The technique used simply originated from a few clinical cases in which we were confronted with an absent or destroyed umbilicus. Previously described techniques for neo-umbilicoplasty were unsatisfying or seemed too complex in our hands. We introduce this easy, safe and reproducible technique which in our experience resulted in a very acceptable newly formed umbilicus.

(c) 2005 The British Association of Plastic Surgeons. Published by Elsevier Ltd. All rights reserved.
\end{abstract}

Reconstruction of a destroyed umbilicus after umbilical herniorrhaphy was first reported by Mc Millan in 1955. Nowadays it can be advocated in cases of congenital absence (bladder exstrophy, gastroschisis, omphalocoele, cloacal exstrophy), or after loss due to inflammatory destruction (periumbilical necrotising fasciitis, umbilical sepsis), surgical procedures (umbilical herniorrhaphy, abdominoplasty, laparotomy) or excision for skin cancer.

The surgical technique to reconstruct a totally absent umbilicus can follow two different principles. A number of techniques use a small piece of skin or a pedicled flap of variable size that remains attached to the abdominal fascia to create the basis of the umbilicus for a small tubular structure. ${ }^{1-5}$ Sometimes this can be combined with a skin or cartilaginous graft. ${ }^{6}$ Other techniques do not rely

\footnotetext{
Presented at the International Symposium, ASAPS meeting, April 15-21 2004, Vancouver, Canada.

* Corresponding author. Tel.: +41 21966 7000; fax: +4121 9667010.

E-mail address: m.pfulg@laclinic.ch (M. Pfulg).
}

on the unpredictable vascularisation from the deeper abdominal wall and use the neighbouring skin from the abdominal wall to create the depression and/or the tubular structure of the umbilicus. ${ }^{7-14}$ In addition, secondary healing can be used to create the umbilical bottom. ${ }^{15}$

\section{Surgical technique}

A triangular skin flap is designed within the elliptical skin excision over the umbilicus either in a vertical or horizontal direction. One side of the triangular flap is attached to the remaining skin border. This side of the triangle measures about $4 \mathrm{~cm}$ while the other two borders measure 7 and $6 \mathrm{~cm}$, respectively (Fig. 1). After wide suprafascial undermining, correction is performed of the rectus diastasis. Over the longest side of the triangle, the flap is folded onto itself (Fig. 2) and sutured upon itself (Fig. 3). The tip of this conical skin structure is then firmly attached to the fascia of the abdominal wall by a $2 / 0$ resorbable suture (Fig. 4). The 


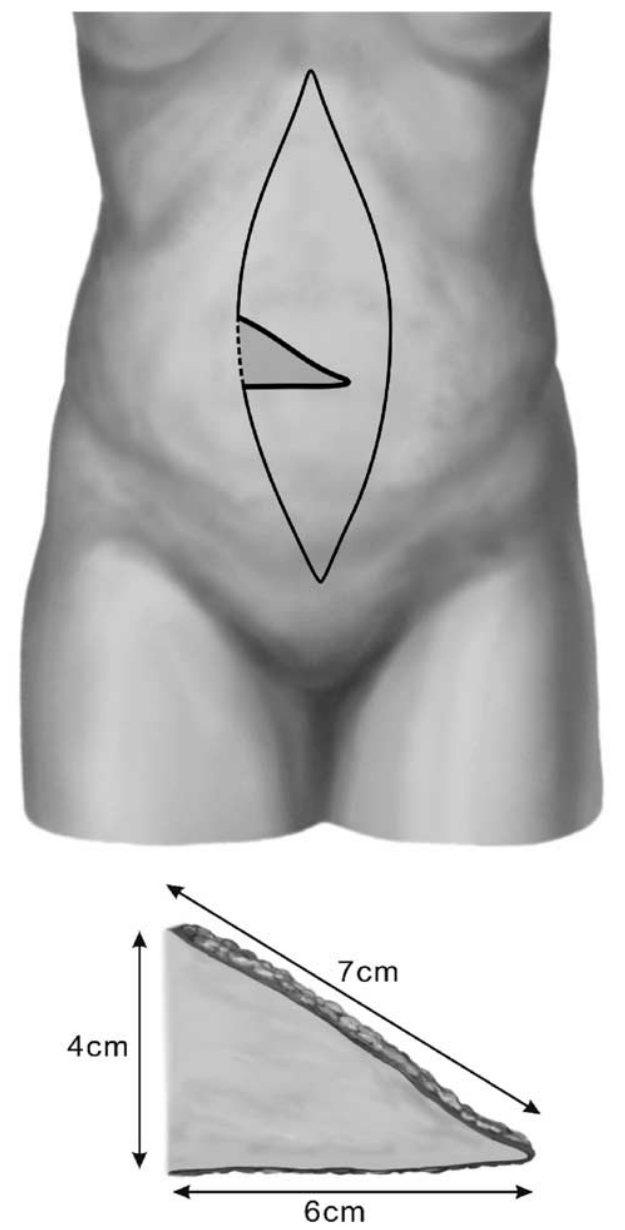

Figure 1 Flap design.

redundant skin around the neo-umbilicus is resected and skin closure is performed (Fig. 5).

Two clinical cases are shown (Figs. 6 and 7).

\section{Discussion}

The construction of a neo-umbilicus is often

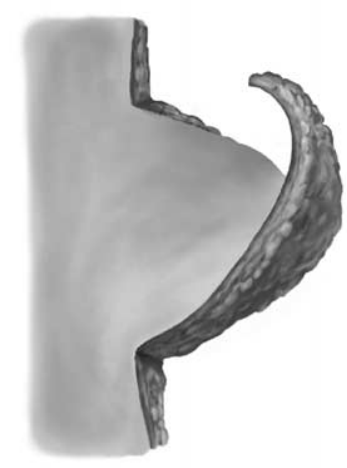

Figure 2 Folding of flap.

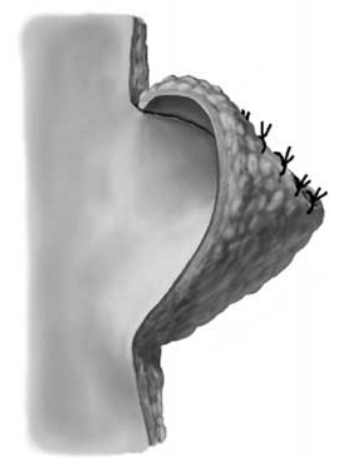

Figure 3 Suturing the flap upon itself.

required after a previous abdominoplasty. In some techniques of suprapubic skin resection, the umbilicus is not resected but completely detached from the underlying fascia. If a secondary abdominoplasty needs to be performed with further and wider resection of excess of skin, often the umbilicus needs to be resected. In other techniques with circum-umbilical skin resection and pursestring tightening, the remaining umbilicus is extremely deformed and can no longer be used. Often patients consult after a total resection of the umbilicus following hernia surgery or complicated laparotomies. More exceptional indications are bladder exstrophia ${ }^{10,16}$ and umbilical hypogenesis. ${ }^{1,17}$

The neo-umbilicus should have a natural morphology, a sufficient and prominent depression and must be created without causing too many additional scars.

Opinions differ on what a normal umbilicus should look like. Most favour almond or slight $\mathrm{T}$-shaped with the longest axis in the vertical direction. ${ }^{18}$ The body morphology of each patient

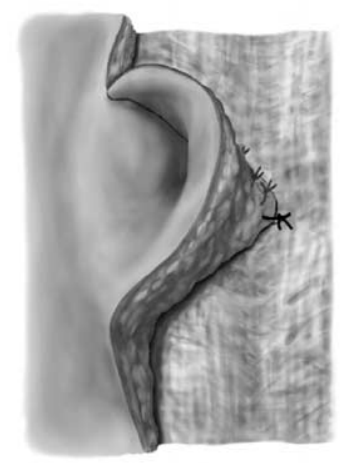

Figure 4 Suturing the resulting cone to the abdominal wall fascia. 


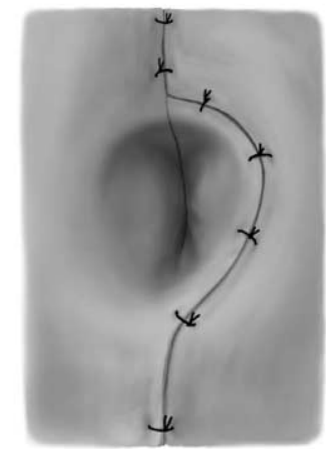

Figure 5 Abdominal wound closure.
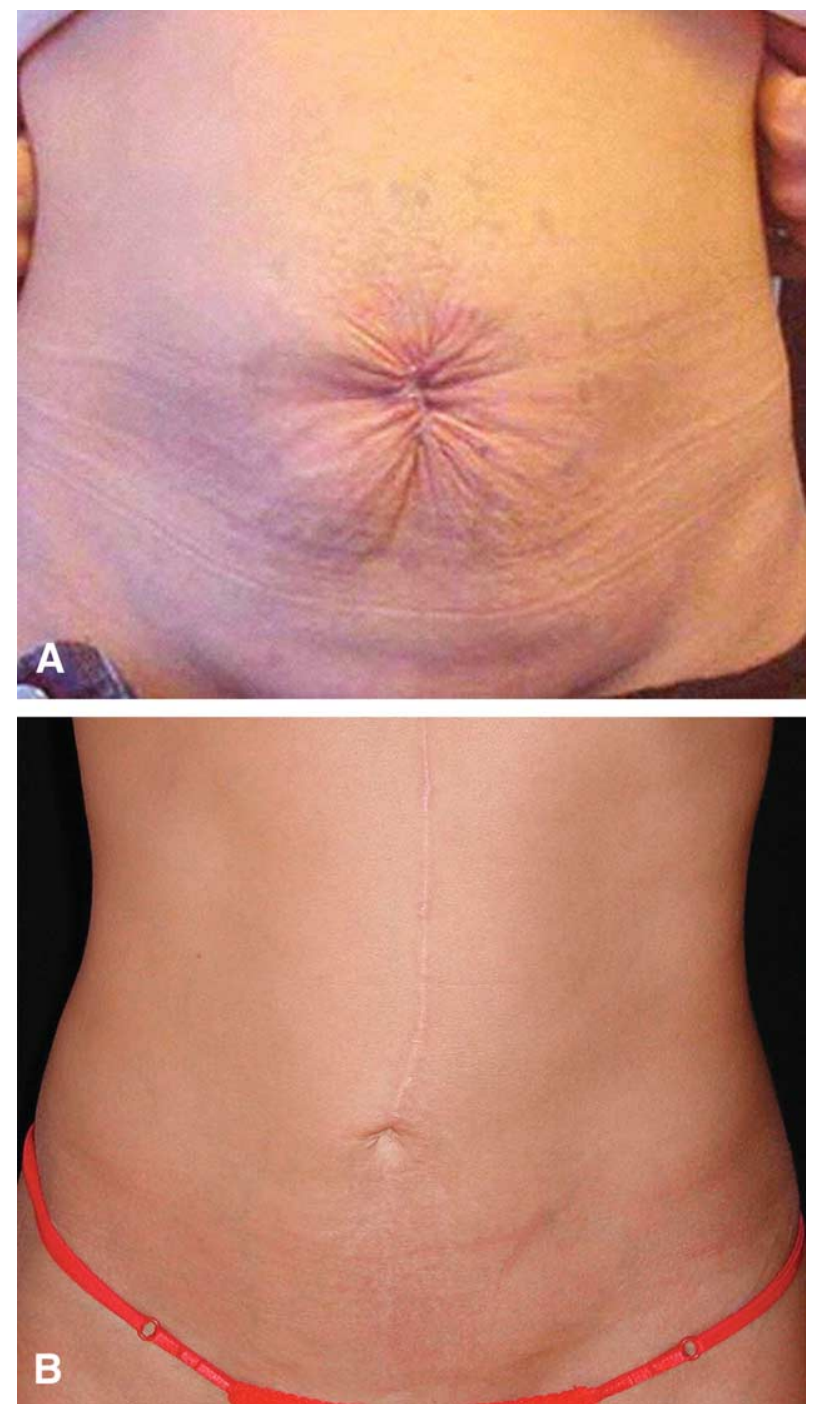

Figure 6 (a) Case 1, preoperative frontal view. (b) Case 1, postoperative frontal view.
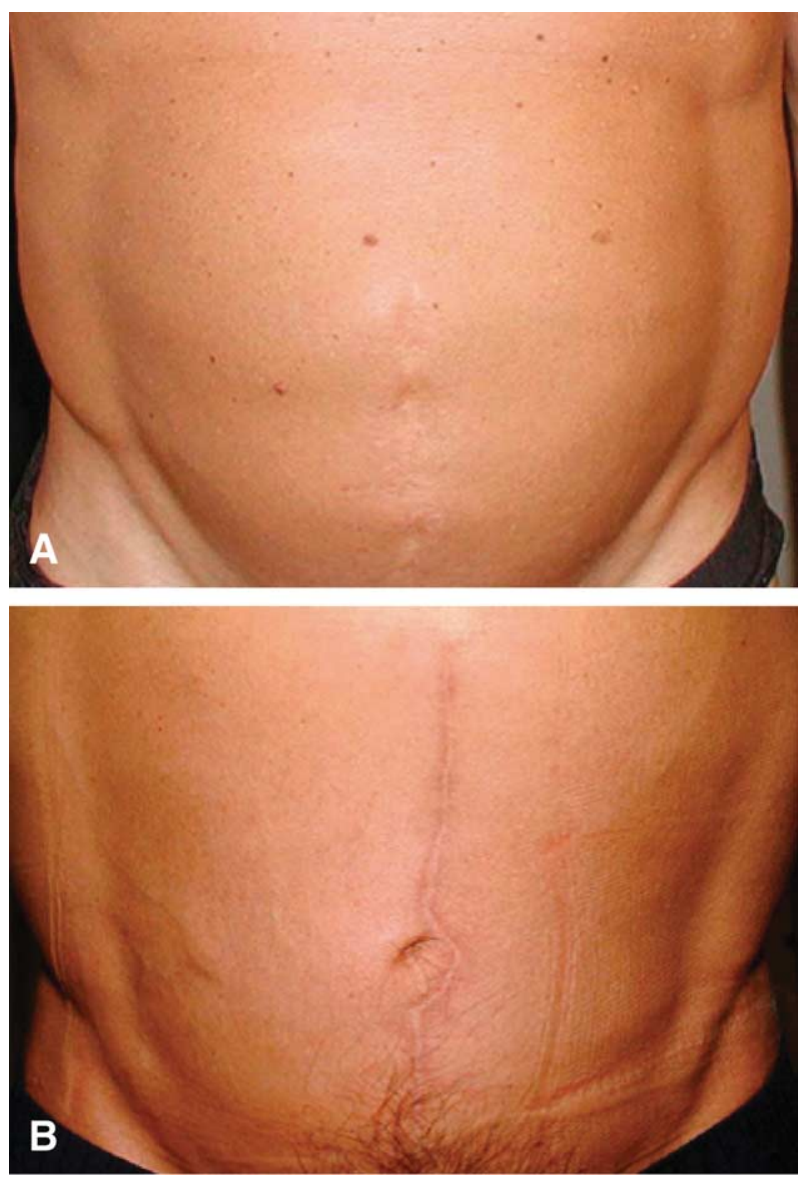

Figure 7 (a) Case 2, preoperative frontal view. (b) Case 2, postoperative frontal view.

has an important influence. The umbilicus depression usually reaches down to the umbilical fascia. It should be placed about $3 \mathrm{~cm}$ above the superior iliac spine or at the highest level of the iliac crest. ${ }^{19,20}$ In the majority of cases, a horizontal skin fold is seen in the upper part of the umbilicus creating a small superior hood. ${ }^{18,21}$

Almost all reconstructed umbilici come along with a horizontal or a vertical scar on the skin of the abdominal wall. This is necessary to decrease the amount of skin around the exterior circumference of the umbilicus in order to obtain sufficient depth of the umbilicus. Marconi and later Bartsich have described purse-string methods. ${ }^{3,22}$ Although this is a very simple technique, the long term results have not been described. The question is, as with the circumareolar mastopexia, if the circular scar will not stretch and so the umbilicus flatten.

The aim of this simple technique is to create a harmonious umbilicus of adequate size, orientation and depth together with a natural shape. The main advantage of this original shape is that it is simple, reproducible and has very few complications. On the other hand, this umbilicoplasty technique needs 
to be combined with either a vertical or horizontal scar over the umbilical position to be able to guarantee sufficient size of the umbilicus. Long term results of over 2 years have confirmed the natural appearance of the neo-umbilicus. We consider this technique as our preference in vertical scar abdominoplasties and umbilical reconstructions.

\section{References}

1. lida N, Ohsumi N. Reconstruction of umbilical hypogenesis accompanied by a longitudinal scar. Plast Reconstr Surg 2003;111:322-5.

2. Itoh Y, Arai K. Umbilical reconstruction using a cone-shaped flap. Ann Plast Surg 1992;28:335-8.

3. Marconi F. Reconstruction of the umbilicus: a simple technique. Plast Reconstr Surg 1995;95:1115-7.

4. Shinohara $\mathrm{H}$, Matsuo K, Kikuchi $\mathrm{N}$. Umbilical reconstruction with an inverted C-V flap. Plast Reconstr Surg 2000;105: 703-5.

5. Yotsuyanagi T, Nihei $Y$, Sawada $Y$. A simple technique for reconstruction of the umbilicus, using two twisted flaps. Plast Reconstr Surg 1998;102:2444-6.

6. Matsuo K, Kondoh S, Hirose T. A simple technique for reconstruction of the umbilicus, using a conchal cartilage composite graft. Plast Reconstr Surg 1990;86:149-51.

7. Lee SL, DuBois JJ, Greenholz SK, Huffman SG. Advancement flap umbilicoplasty after abdominal wall closure: postoperative results compared with normal umbilical anatomy. J Pediatr Surg 2001;36:1168-70.

8. Borges AF. Reconstruction of the umbilicus. Br J Plast Surg 1975;28:75-6.
9. Miller MJ, Balch CM. 'Iris' technique for immediate umbilical reconstruction. Plast Reconstr Surg 1993;92:754-6.

10. Feyaerts A, Mure PY, Jules JA, Morel-Journel $N$, Mouriquand $\mathrm{P}$. Umbilical reconstruction in patients with exstrophy: the kangaroo pouch technique. J Urol 2001;165: 2026-7 [discussion 28].

11. Sugawara $\mathrm{Y}$, Hirabayashi S, Asato H, Yoshimura K. Reconstruction of the umbilicus using a single triangular flap. Ann Plast Surg 1995;34:78-80.

12. Baack BR, Anson G, Nachbar JM, White DJ. Umbilicoplasty: the construction of a new umbilicus and correction of umbilical stenosis without external scars. Plast Reconstr Surg 1996;97:227-32.

13. Jamra FA. Reconstruction of the umbilicus by a double $V-Y$ procedure. Plast Reconstr Surg 1979;64:106-7.

14. Onishi K, Yang YL, Maruyama Y. A new lunch box-type method in umbilical reconstruction. Ann Plast Surg 1995;35: 654-6.

15. Santanelli F, Mazzocchi M, Renzi L, Cigna E. Reconstruction of a natural-looking umbilicus. Scand J Plast Reconstr Surg Hand Surg 2002;36:183-5.

16. Pinto PA, Stock JA, Hanna MK. Results of umbilicoplasty for bladder exstrophy. J Urol 2000;164:2055-7.

17. Krummel TM, Sieber WK. Closure of congenital abdominal wall defects with umbilicoplasty. Surg Gynecol Obstet 1987; 165:168-9.

18. Craig SB, Faller MS, Puckett CL. In search of the ideal female umbilicus. Plast Reconstr Surg 2000;105:389-92.

19. Koshy CE, Taams KO. Umbilicoplasty. Plast Reconstr Surg 1999;104:1203-4.

20. Dubou R, Ousterhout DK. Placement of the umbilicus in an abdominoplasty. Plast Reconstr Surg 1978;61:291-3.

21. Choudhary S, Taams KO. Umbilicosculpture: a concept revisited. Br J Plast Surg 1998;51:538-41.

22. Bartsich SA, Schwartz MH. Purse-string method for immediate umbilical reconstruction. Plast Reconstr Surg 2003;112: $1652-5$. 